\section{Acute ischemic stroke management in a patient with ventricular assist device}

\section{Çisil İrem Özgenç Biçer*, Işıl Kalyoncu Aslan, Irmak Salt and Eren Gözke}

Department of Neurology, University of Health Sciences, Fatih Sultan Mehmet Training and Research Hospital, Hastane Sokak no:1/8 İçerenköy, Ataşehir 34752 Istanbul, Turkey

\section{Introduction}

Ventricular assist device is a portable machine which is also called an artificial heart for the patients who have terminal heart failure. The device maintains the heart's vital functions until the suitable donor is found for the heart transplantation. It can be applied to either ventricles or both (biventricular). Although the device provides independence for the patient, it also has life-threatening complications. Such as infection, stroke secondary to thromboembolism, hemorrhage depending on anticoagulant use, right heart failure... and most of the time it is really hard to manage those complications. We will present a case, who had ischemic stroke as a complication of VAD even though he has been using aspirin, warfarin and had effective INR value.

\section{Case report}

A 50 year old male patient had heart failure secondary to myocarditis when he was 40.5 years ago, he had an implanted ventricular assist device while he was on a transplant list. Since then he has been using warfarin $5 \mathrm{mg}$, carvedilol 25 mg losartan $25 \mathrm{mg}$ and aspirin $100 \mathrm{mg}$ every day. He's seen by a cardiologist periodically (every two weeks) and his INR value has always been at the protective/effective interval. The patient was brought to the emergency department with a sudden onset of left sided hemiparesis and confusion. In neurological examination his cooperation and orientation was limited, eyes deviated to right, pupils were isochoric, direct and indirect light reflexes both $+/+$, left sided facial droop, dysarthria, left hemiparesis, left hemihypoesthesia and left neglect. Babinski was positive on the left side. Cerebellar tests and visual examinations couldn't be evaluated because of the cooperation difficulty. His National Institutes of Health Stroke Scale (NIHSS) was calculated as 13. Initial CT angiogram of head and neck reported as acute right $\mathrm{m} 1$ branch occlusion. MR imagining was absent because VAD is not suitable. The
More Information

*Address for Correspondence: Çisil İrem Özgenç Biçer, MD, Neurology Resident, Department of Neurology, University of Health Sciences, Fatih Sultan Mehmet Training and Research Hospital, Turkey, Tel: +905355585985;

Email: cisiliremozgenc@gmail.com

Submitted: November 05, 2020

Approved: December 21, 2020

Published: December 23, 2020

How to cite this article: Biçer $\mathrm{ClO}$, Aslan IK, Salt I, Gözke E. Acute ischemic stroke management in a patient with ventricular assist device. J Cardiol Cardiovasc Med. 2020; 5 : 174-175

DOI: 10.29328/journal.jccm.1001106 ORCiD: orcid.org/0000-0002-4582-3495

Copyright: (c) 2020 Biçer ClO, et al. This is an open access article distributed under the Creative Commons Attribution License, which permits unrestricted use, distribution, and reproduction in any medium, provided the original work is properly cited.

Check for updates

OPEN ACCESS

patient had acute ischemic stroke according to physical and radiological examinations. INR value ended up 2.92, above 1.7 is absolute contraindication for alteplase treatment so it wasn't applied. Because he had right $\mathrm{m} 1$ branch occlusion, the patient was taken directly to the interventional radiology unit for mechanical thrombectomy procedure during the second hour of the onset of his complaint. After 40 minutes, complete reperfusion (the thrombolysis in cerebral infarction (TICI:3) was supplied and the patient was taken to the neurology intentional care unit. No cerebral hemorrhagic transformation has occurred. After consultation with cardiology and cardiovascular surgery, medications have been planned as warfarin (INR intended to be 3-3.5) and as a $100 \mathrm{mg}$ after nine days of medical monitoring there was no data about high blood pressure, elevated lipid levels or other pathological vital values. He was released from the hospital with NIHSS: 0 and Modified Rankin Scale (MRS): 0.

\section{Discussion}

Stroke is a life-threatening disease which makes most of the patients dependent on others because of the brain damage. Especially large vessel occlusions are the main reason, the patients to be bedridden or at least physically disabled. 
Therefore mechanical thrombectomy is a great chance for stroke patients if done in good hands. Gives the patients their independence back or at least shortens the rehabilitation periods, decreasing the risk of vascular dementia. Patients who implanted VAD need to use anticoagulants and antiplatelets in order to prevent thromboembolic complications. Most of the researches show that stroke is a frequent (14\%) complication for them. Ratio is very close between ischemic and hemorrhagic. There is not enough research for new oral anticoagulation therapy so that makes warfarin as an only choice for anticoagulation. It is known that when the INR is above 4 , hemorrhagic stroke incidence increases evidently. To decrease the risk of hemorrhage, it is important to maintain optimum blood pressure for a long term period. No histological analysis was performed for the material but it has probably thrombotic origin as the neuroradiologist's impression that's why INR aimed to be between 3- 3.5 and he has continued taking aspirin as before.

\section{Results}

People with VAD have higher risks of thrombosis and the alteplase option is really limited for acute ischemic stroke patients. Mechanical thrombectomy seems to be the only choice for most of the cases. For these patients blood pressure regulation is a must! INR should be evaluated more commonly, and for those who had thrombus complications before, INR should be between 3-3.5 considering the risk of hemorrhage [1-13].

\section{References}

1. From R, Hasan D, Froehler M, Goerbig-Campbell J. Stroke and Left, Ventricular Assist Device (LVAD). Open J Anesthesiol. 2013; 3: 51-56.

2. Yuan N, Arnaoutakis GJ, George TJ, Allen JG, Ju DG, et al The spectrum of complications following, left ventricular assist device placement. J Card Surg. 2012; 27: 630-638.

PubMed: https://pubmed.ncbi.nlm.nih.gov/22978843/

3. Kirklin JK, Naftel DC, Kormos RL, Pagani FD, Myers SL, et al. Interagency Registry for Mechanically, Assisted Circulatory Support (INTERMACS) analysis of pump thrombosis in the, Heart Mate II left ventricular assist device. J Heart Lung Transplant. 2014; 33: 12-22. PubMed: https://pubmed.ncbi.nlm.nih.gov/24418730/

4. Adams HP, Jr., del Zoppo G, Alberts MJ, et al. Guidelines for the Early Management of Adults with Ischemic Stroke: A Guideline from the American Heart Association/American Stroke Association Stroke Council, Clinical Cardiology Council, Cardiovascular Radiology and Intervention Council, and the Atherosclerotic, Peripheral Vascular Disease and Quality of Care Outcomes in Research, Interdisciplinary Working Groups. Circulation. 2007; 115: 478-534.

5. Parikh NS, Cool J, Karas MG, Boehme AK, Kamel H. Stroke Risk and Mortality in Patients With Ventricular Assist Devices. Stroke. 2016; 47: 2702-2706.

PubMed: https://pubmed.ncbi.nlm.nih.gov/27650070/

6. Hassett C, Cho SM, Rice C, Uchino K. The Etiology of Left Ventricular Assist Device Associated Ischemic Stroke (P6.242). Neurology. 2018; https://n.neurology.org/content/90/15_Supplement/P6.242

7. Bishawi M, Joseph J, Patel C, Schroder J, Daneshmand M, et al. Risk Factors for Stroke on Left Ventricular Assist Devices. J Cardiac Surg. 2018; 33: 348-352.

PubMed: www.ncbi.nlm.nih.gov/pubmed/29774592

8. Menon AK, Götzenich A, Sassmannshausen H, Haushofer M, Autschbach R, et al. Low stroke rate and few thrombo-embolic events after HeartMate II implantation under mild anticoagulation. Eur $\mathrm{J}$ Cardiothorac Surg. 2012; 42: 319-323.

PubMed: https://pubmed.ncbi.nlm.nih.gov/22398471/

9. DeVore AD, Stewart GC. The Risk of Stroke on Left Ventricular Assist Device Support. JACC Heart Failure. 2017; 5: 712-714. PubMed: https://pubmed.ncbi.nlm.nih.gov/28958346/

10. Cho SM, Moazami N, Katz S, Bhimraj A, Shrestha KN, et al. Stroke Risk Following Infection in Patients with Continuous- Flow Left Ventricular Assist Device. Neurocrit Care. 2019; 31: 72-80. PubMed: www.ncbi.nlm.nih.gov/pubmed/30644037

11. Patil CG, Long EF, Lansberg MG. Cost-effectiveness analysis of mechanical thrombectomy in acute ischemic stroke. J Neurosurg. 2009; 110: 508-513.

PubMed: https://pubmed.ncbi.nlm.nih.gov/19025358/

12. Morici N, Varrenti M, Brunelli D, Perna E, Cipriani M, et al. Antithrombotic therapy in ventricular assist device (VAD) management: From ancient beliefs to updated evidence. A narrative review. IJC Heart Vasculature. 2018; 20: 20-26

PubMed: https://pubmed.ncbi.nlm.nih.gov/30229131/

13. Cao C, Martinelli A, Spoelhof B, Llinas R, Marsh E. In Potential Stroke Patients on Warfarin, the International Normalized Ratio Predicts Ischemia. Cerebrovasc Dis Extra. 2017; 7: 111-119.

PubMed: https://pubmed.ncbi.nlm.nih.gov/28803231/ 